\title{
Career Opportunities for Students
}

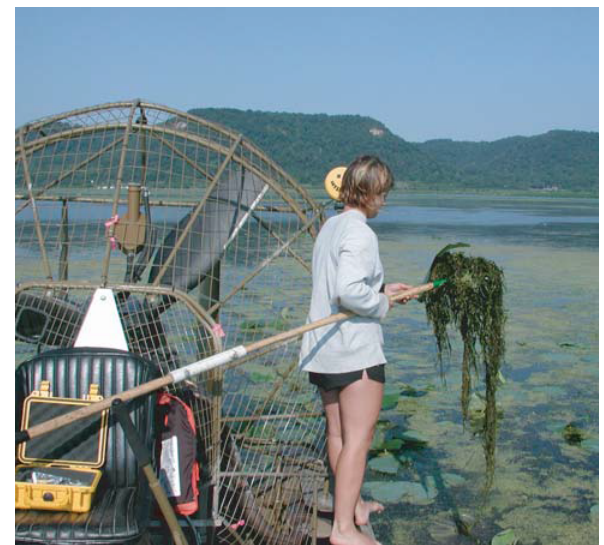

\section{The U.S. Geological Survey}

The U.S. Geological Survey (USGS) offers diverse employment opportunities for students in bology, hydrology, computer science, cartography, geology, administration, and many other fields.

To learn about job opportunities for students within the USGS, check the Web site: www.usgs.gov/ohr/oars/index.html

For questions, contactLinda Ott, 608.781 .6264 lott@usgs.gov

To apply for jobs with the USGS, use the USA Jobs Website: usa.jobs.gov

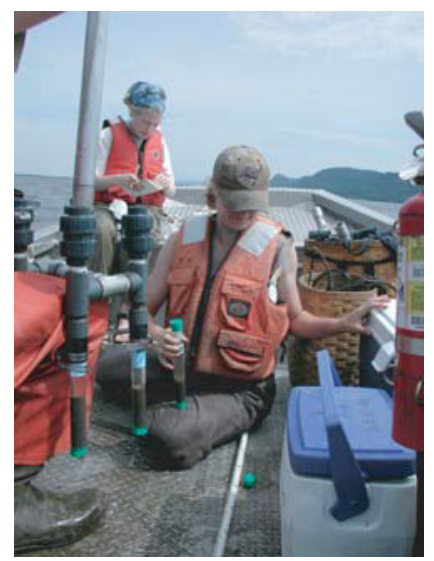

The Upper Midwest Environmental Sciences Center

Volunteering

What a great way to build up your resume and learn new skills! We have many opportunities to volunteer at UMESC. For information about volunteering, contact-

Randy Hines 608.781 .6398 rkhines@usgs.gov

JC Nelson (GIS lab) 608.781 .6370

jcnelson@usgs.gov

Shirley Yuan

(Water Quality lab)

608.781.6302

xyuan@usgs.gov

\section{College Students}

Our Center has programs for both undergraduate and graduate students including paid hourly employment, internships, and research assistantships.

For more information for students from UW-L or WTC, contact the following:

\section{University of Wisconsin-La Crosse}
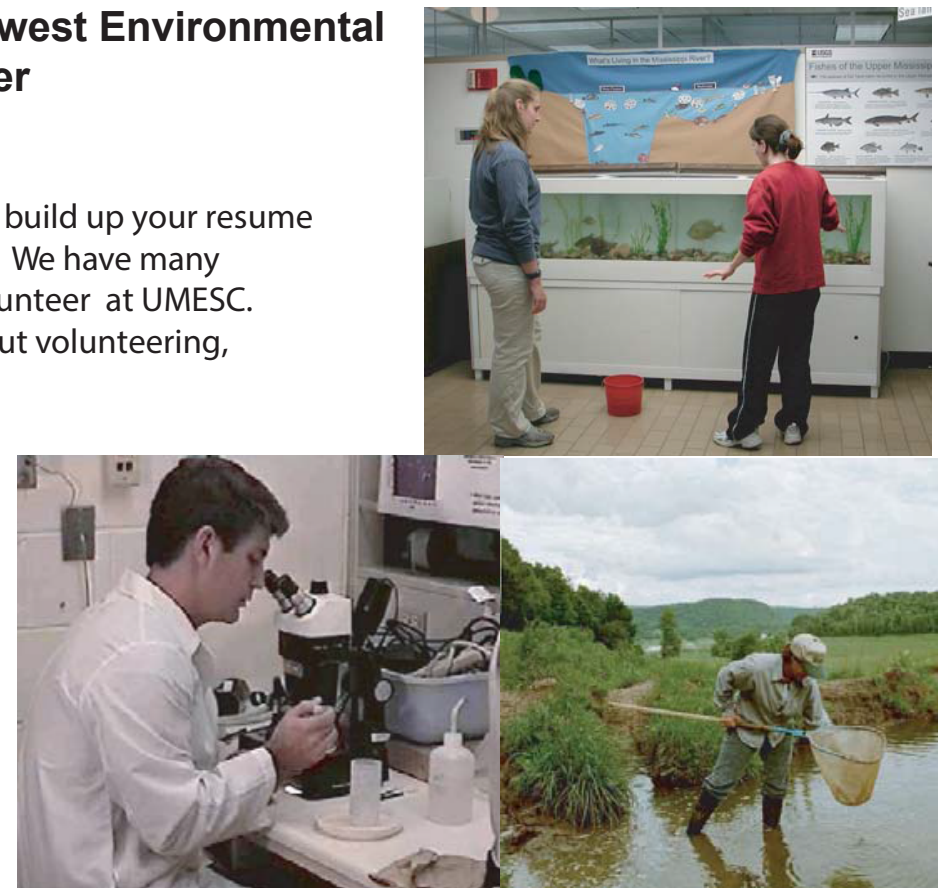

For information about job opportunities for students from other colleges, contact-

Linda Ott

608.781.6264

lott@usgs.gov

Randy Hines

608.781 .6398

rkhines@usgs.gov

Dr. Roger Haro

608.785.6970

haro.roge@uwlax.edu

Dr. Robin Tyser

608.785.6992

tyser.robi@uwlax.edu

Western Technical College

Student E mployment Office 608.785.9440

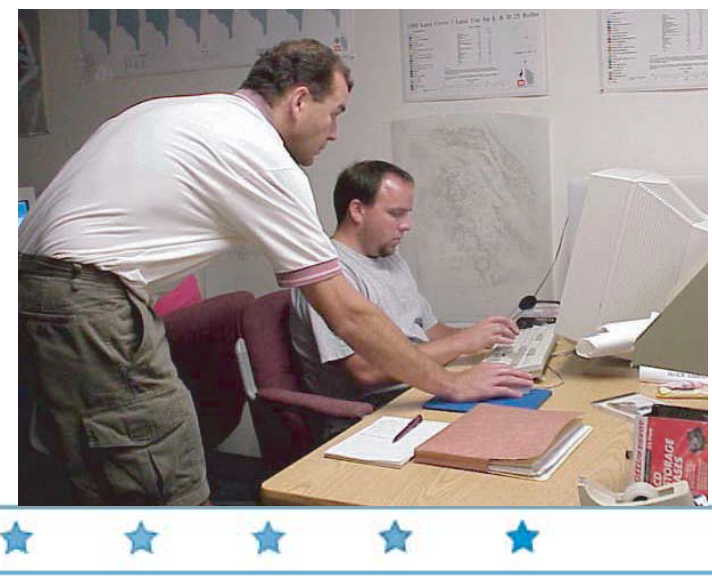

